\title{
Gastrointestinal Bleeding as a Late Complication After Gastric-Bypass: A Case Report
}

\author{
Folco Solimene*, Ferda Gronki, Matteo Giardini and Georgios Peros \\ Department of Surgery, Cantonal Hospital Winterthur, Winterthur, Switzerland
}

*Corresponding author: Folco Solimene, Department of Surgery, Cantonal Hospital Winterthur, Brauerstrasse 15,

Winterthur, Zurich, 8401, Switzerland

\begin{tabular}{|c|c|}
\hline ARTICLE INFO & ABSTRACT \\
\hline Received: 㴔 August 24, 2020 & \multirow{6}{*}{$\begin{array}{l}\text { Surgery is considered to be an effective and long-term treatment for individuals } \\
\text { with severe obesity and over the past } 20 \text { years, bariatric surgery has gained immense } \\
\text { popularity. Laparoscopic Roux-en-Y gastric bypass (LRYGB) surgery as well as sleeve } \\
\text { gastrectomy (SG), in particular, have become two of the most widely-performed bariatric } \\
\text { procedures world-wide[1]. Whilst these operations are deemed safe in expert hands } \\
\text { severe and potentially life-threatening complications have been reported. Optimal } \\
\text { management of these complications, however, usually poses a challenge for both genera } \\
\text { surgeons and gastroenterologists. Although the diagnosis and subsequent management } \\
\text { of early complications including anastomotic leaks, venous thromboembolic events } \\
\text { and intestinal obstruction are well documented, those for late complications, with the } \\
\text { exception of internal hernias, are less well defined. We present a rare case of a late bleeding } \\
\text { from the gastro-jejunal anastomosis } 19 \text { months following LRYGB surgery, including the } \\
\text { successful treatment performed in a non- specialist center for bariatric surgery. }\end{array}$} \\
\hline Published: September 04, 2020 & \\
\hline \multirow{5}{*}{$\begin{array}{l}\text { Citation: Folco Solimene, Ferda Gronki, } \\
\text { Matteo Giardini, Georgios Peros. } \\
\text { Gastrointestinal Bleeding as a Late } \\
\text { Complication After Gastric-Bypass: A Case } \\
\text { Report. Biomed J Sci \& Tech Res } 30(1)- \\
\text { 2020. BJSTR. MS.ID.004890. }\end{array}$} & \\
\hline & \\
\hline & \\
\hline & \\
\hline & $\begin{array}{l}\text { Abbreviations: LRYGB: Laparoscopic Roux-en-Y Gastric Bypass; SG: Sleeve Gastrectomy; } \\
\text { WHO: World Health Organization; BMI: Body Mass Index; IFSO: International Federation } \\
\text { for the Surgery of Obesity; MU: Marginal Ulcers; GI: Gastrointestinal }\end{array}$ \\
\hline
\end{tabular}

\section{Introduction}

According to the World Health Organization (WHO), obesity is defined as a Body Mass Index (BMI) over $30 \mathrm{~kg} / \mathrm{m}^{2}$. The treatment of obesity and adiposity-based chronic diseases has become a major health concern [2]. Organizations such as the International Federation for the Surgery of Obesity and Metabolic Disorders (IFSO) play an integral role in educating both the metabolic surgical and the medical community about the best management of patients who have undergone bariatric surgery. Based on IFSO data, the two most common procedures for obesity are the LRYGB (35\%) and the SG (47\%) [3]. Although rare, post-operative complications can occur. These are defined as either early complications including bleeding, anastomotic leak, abscess, kinking and pulmonary thromboembolism, or late complications such as stenosis, anastomotic fistulas, dumping syndrome, marginal ulcers (MU) or internal hernia [4]. Management of early complications are well documented in the literature, however there are currently limited evidence-based guidelines on the treatment of late complications, perhaps due to their less common occurrence [5]. In the following case report, we present a rarely-reported late complication in the form of an acute bleeding anastomotic ulcer.

\section{Case Presentation}

A 55-year-old female patient, presented to the Emergency Department of a non bariatric center following several episodes of melena and syncope. Nineteen months prior to her presentation she underwent a LRYGB procedure for morbid obesity in another hospital (BMI $38.5 \mathrm{~kg} / \mathrm{m}^{2}$, WHO grade II). Unfortunately, 24 hours following the operation the patient developed peritonism due to a small intestinal lesion and was successfully treated with a laparoscopic re-operation. Of note her previous medical history included a $H$. pylori infection two years prior to the LRYGB, which was eradicated with antibiotics and proton pump inhibitor 
(PPI) therapy via Dexlansoprazole 60mg once daily. The use of non-steroidal anti-inflammatory drugs (NSAIDs), steroids or oral anticoagulants prior to her presentation in the Emergency Department was denied. Analgesia in the form of $1 \mathrm{gr}$ metamizole for epigastric pain was taken the day before. The most recent gastroscopy and colonoscopy, performed about four weeks prior to the LRYGB as part of routine pre-operative assessment, was unremarkable. At presentation her vital parameters were stable with blood pressure $136 / 65 \mathrm{mmHg}$, regular pulse $88 /$ minute, normal respiratory rate, and a temperature of $37.1^{\circ} \mathrm{C}$. Her BMI was measured to be $25.6 \mathrm{~kg} / \mathrm{m}^{2}$. On clinical examination, there was no evidence of an acute abdomen with only light pain on palpation in the lower abdomen. A digital rectal examination demonstrated dark brown feces.

Laboratory findings indicated evidence of bleeding with an initial Hemoglobin value of $9.5 \mathrm{~g} / \mathrm{dl}$ at presentation followed by a subsequent decrease to $7.7 \mathrm{~g} / \mathrm{dl}$ one hour later. The remainder of the blood work was unremarkable with normal Thrombocytes and coagulation parameters (Quick 73\%, INR 1.14). Initial fluid resuscitation with crystalloids was commenced, and high-dose PPI with Pantoprazole 40mg was administered intravenously every 12 hours. Two hours following presentation, an emergency upper gastrointestinal endoscopy was performed by a senior gastroenterologist, whereby the Gastrojejunal-anastomosis was identified $45 \mathrm{~cm}$ from the tooth, but there was no evidence of active bleeding. Two anastomotic MU (Forrest IIa and Forrest III [6]) were, however, identified and local injection with adrenaline and metal clipping of the non-bleeding visible vessel was performed (Figure 1). This treatment protocol was performed according to the European Society of Gastrointestinal Endoscopy (ESGE) Guidelines [4,7-10]. Following the procedure, the patient was transferred to the intermediate care unit for further monitoring and initiation of fluid oral feeding. Hemoglobin values remained stable and no blood transfusion was initially required. A control gastroscopy 2 days later showed no bleeding, but two more metal clips were applied to the same non bleeding vessel. Unfortunately, 4 days following initial presentation, fresh bleeding was suspected as the patient displayed dizziness and hypotension, but no melena or hematemesis.

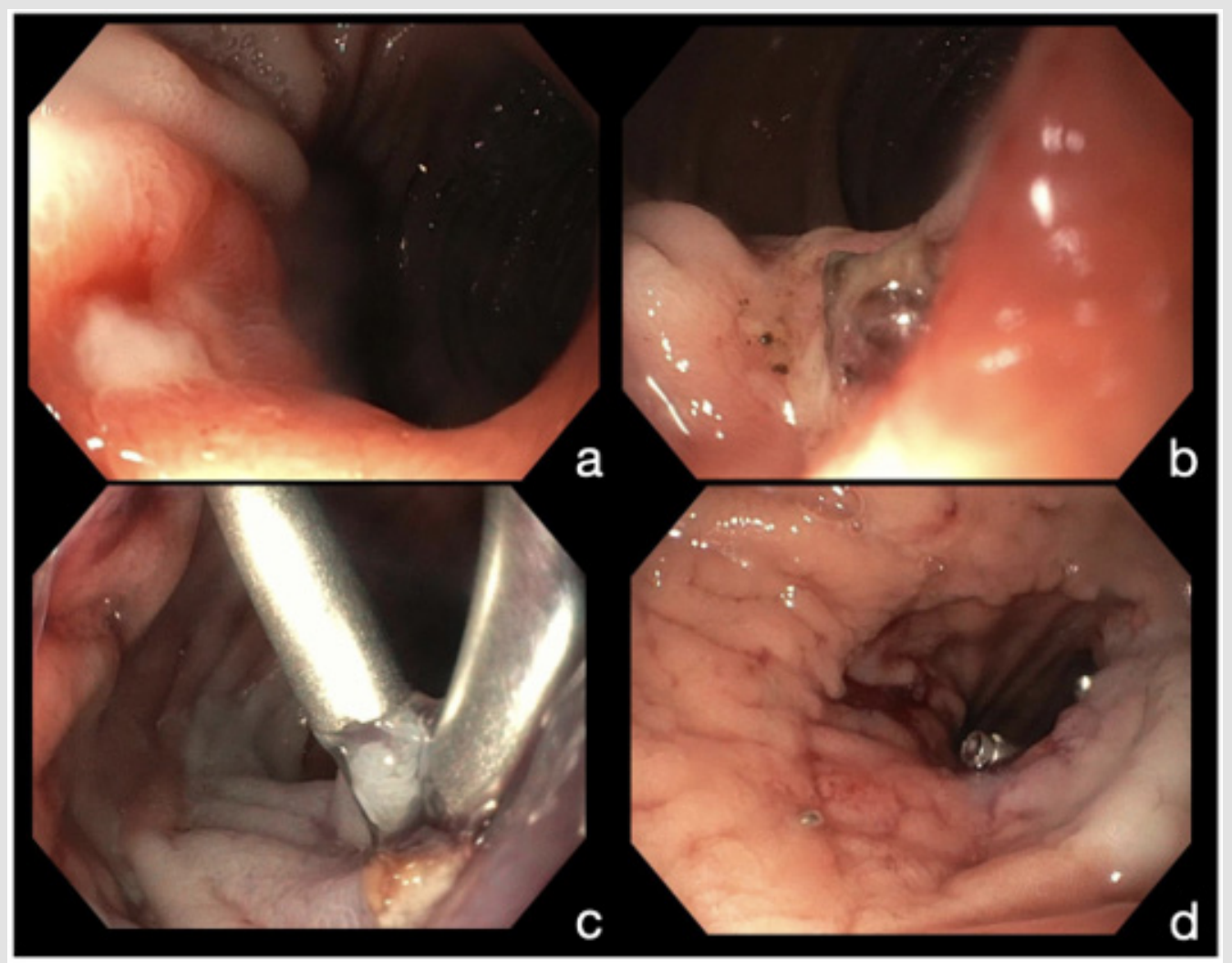

Figure 1: First Endoscopy,

a) Marginal ulcers Forrest III;

b) Marginal ulcers Forrest IIa;

c) Applied Clips;

d) Overview of the GJ anastomosis. 
Blood results showed a further Hemoglobin drop to $5.9 \mathrm{~g} / \mathrm{dl}$ and the patient received 2 units of red blood cell transfusion. A third gastroscopy was also performed, interestingly no active bleeding, no fresh intraluminal blood and no dislocation of the metal clips were found. A second non-bleeding vessel was, however, identified and clipped. Following the gastroscopy, the patient underwent an abdominal CT scan with intravenous and arterial contrast as well as a colonoscopy to exclude other areas of active bleeding. As none were identified, thromboprophylaxis therapy was discontinued and no further complications were observed. The final control gastroscopy was unremarkable and the Hemoglobin value remained stable at $7.6 \mathrm{~g} / \mathrm{dl}$. Following 9 days of hospitalization, the patient was finally discharged home with PPI therapy via Esomeprazole $40 \mathrm{mg}$ twice daily for 6 weeks. Due to diarrhoeal side-effects, however, this was later converted to Dexlansoprazole. Routine follow-up was otherwise uneventful with no recurrence of symptoms being reported.

\section{Discussion}

Gastrointestinal (GI) bleeding often poses a challenge for gastroenterologists and general surgeons alike. This is often the case due to difficulties in identifying the source of bleeding, regardless of previous abdominal surgical history. In LRYGB performed for adiposity, the literature reports acute early GI bleeding as a common complication occurring between $2.6 \%$ to $11 \%[4,7-9]$ of the cases, with the source usually occurring from the anastomosis or staple line. The incidence of bleeding as a late complication is estimated up to $5 \%[4,5,8,11]$, however data is limited and is only described in a few case reports. The main cause is believed to be due to bleeding marginal ulcers (MU). The characteristics of MU, its complications and management were analyzed in a systematic review from Coblijn et al. [12], involving 41 studies and a total of 16,987 patients. In symptomatic patients $(n=777)$, epigastric burn was the most frequently reported symptom (56.8\%) and of these patients, 117 (15.1\%) were found to have bleeding. Furthermore Coblijn and his colleagues reported that the incidence of MU was found to be underestimated and could be correlated to the preoperative presence of $H$. pylori, as was the case with our patient. Whilst most would agree that endoscopy is clearly indicated as a part of the management pathway following bariatric surgery when patients are symptomatic, the role of routine surveillance endoscopy in LRYGB remains controversial.

IFSO recommends that postoperative endoscopy should be undertaken routinely for all patients at 1 year and then every 2 to 3 years for patients who have undergone SG or one anastomosis gastric bypass in order to improve early detection of other complications, but following LRYGB an endoscopy should be performed on the basis of upper GI symptoms [13]. Furthermore, while there are currently no evidence-based guidelines to help guide treatment in late complications following LRYGB, the authors feel endoscopic management of bleeding MU should be considered as first-line therapy. This can be safely performed by an experienced gastroenterologist at a non-specialist center for bariatric surgery. The H. pylori should be tested when finding MU and eradication therapy should be performed. Of most importance, however is the critical role of interdisciplinary teamwork in the management of bariatric post-operative complications.

\section{References}

1. Colquitt JL, Pickett K, Loveman E, Frampton GK (2014) Surgery for weight loss in Adults (Review). The Cochrane Collaboration (8): 244.

2. (2020) WHO. Obesity and Overweight Fact Sheet.

3. Ramos A, Fasmbs F, Kow L (2019) The IFSO Global Registry $5^{\text {th }}$ IFSO Global Registry Report. Published by dendrite Clinical Systems.

4. Lim R, Beekley A, Johnson DC, Davis KA (2018) Early and late complications of bariatric operation. Trauma Surgery and Acute Care Open 3(1): 1-7.

5. Palermo M, Acquafresca PA, Rogula T, Duza GE, Serra E (2015) Late surgical complications after gastric by-pass: A literature review. Brazilian archives of digestive surgery 28(2): 139-143.

6. John AH, Forrest NDCF, DJC Shearman (1974) Endoscopy in Gastrointestinal Bleeding. Lancet 2(7877): 394-397.

7. Boules M, Chang J, Haskins IN, Gautam Sharma, Dvir Froylich, et al. (2016) Endoscopic management of post-bariatric surgery complications. World Journal of Gastrointestinal Endoscopy 8(17): 591-599.

8. Rabl C, Peeva S, Prado K (2011) Early and late abdominal bleeding after Roux-En-Y gastric bypass: Sources and tailored therapeutic strategies. Obesity Surgery 21(4): 413-420.

9. Spaw AT, Husted JD (2005) Bleeding after laparoscopic gastric bypass: Case report and literature review. Sugery for Obesity and Related Diseases 1(2): 99-103.

10. Gralnek IM, Dumonceau JM, Kuipers E (2015) Diagnosis and management of nonvariceal upper gastrointestinal hemorrhage: European Society of Gastrointestinal Endoscopy (ESGE) Guideline. Endoscopy 47(10): a1a46.

11. Gupta A, Shah MM, Kalaskar SN, Kroh M (2018) Late postoperative bleeding after Roux-en-Y gastric bypass: Management and review of literature. BMJ Case Reports 11(1): 1-3.

12. Coblijn UK, Lagarde SM, Tuynman JB, Van Meyel JJM, Van Wagensveld BA (2013) Delayed massive bleeding two years after Roux-en-Y gastric bypass. Journal of the Society of Laparoendoscopic Surgeons 17(3): 476480.

13. Brown WA, Johari Halim Shah Y, Balalis G, Ahmad Bashir, Almino Ramos, et al. (2020) IFSO Position Statement on the Role of Esophago-GastroDuodenal Endoscopy Prior to and after Bariatric and Metabolic Surgery Procedures. Obesity Surgery 30(8): 3135-3153. 
ISSN: 2574-1241

DOI: $10.26717 /$ BJSTR.2020.30.004890

Folco Solimene. Biomed J Sci \& Tech Res

(c) (P) This work is licensed under Creative Commons Attribution 4.0 License

Submission Link: https://biomedres.us/submit-manuscript.php

\begin{tabular}{ll} 
BIOMEDICAL & \multicolumn{1}{c}{ Assets of Publishing with us } \\
RESEARCHES & - Global archiving of articles \\
\hline ISS: $2574-1241$ & - Immediate, unrestricted online access \\
\end{tabular}

